\title{
POLITIK HUKUM DOKTRIN PIERCING THE CORPORATE VEIL PADA PENGELOLAAN PERSEROAN TERBATAS DI INDONESIA
}

\author{
Abdurrahman \\ E-mail: Abdurrahman.ab11@gmail.com \\ Mahasiswa S-1 Fakultas Hukum Universitas Sebelas Maret \\ Pujiyono \\ E-mail: Pujifhuns@gmail.com \\ Dosen Fakultas Hukum Universitas Sebelas Maret
}

\begin{abstract}
This article aims to examine the legal politics of the doctrine of Piercing the Corporate Veil in the regulation of Limited Liability Companies in Indonesia. The problems discussed are related to how the legal politics of the Piercing the Corporate Veil doctrine in the management of Limited Liability Companies in Indonesia. The research method used is normative legal research with the nature of prescriptive research using a statute approach. The results of the study indicate that the Piercing the Corporate Veil doctrine can eliminate the previously limited liability of the Company's organs to be unlimited if the Company's organs are proven to have done an act that is detrimental to the Company or third parties.
\end{abstract}

Keywords: limited liability company; Responsibility of Company Organs; Piercing the Corporate Veil

\begin{abstract}
Abstrak
Artikel ini bertujuan mengkaji terkait politik hukum doktrin Piercing the Corporate Veil dalam peraturan Perseroan Terbatas di Indonesia. Permasalahan yang dibahas adalah terkait bagaimana politik hukum doktrin Piercing the Corporate Veil dalam pengelolaan Perseroan Terbatas di Indonesia. Metode penelitian yang digunakan adalah penelitian hukum normatif dengan sifat penelitian preskriptif dengan menggunakan pendekatan statute approach. Hasil penelitian menunjukkan bahwa doktrin Piercing the Corporate Veil dapat menghapuskan pertanggungjawaban organ Perseroan yang sebelumnya terbatas menjadi tidak terbatas jika organ Perseroan terbukti melakukan perbuatan yang merugikan bagi Perseroan maupun pihak ketiga. Kata kunci: Perseroan Terbatas; Pertanggungjawaban Organ Perseroan; Piercing the Corporate Veil
\end{abstract}

\section{A. Pendahuluan}

Perseroan Terbatas (PT) di Indonesia lahir untuk menjadi lembaga ekonomi yang bertujuan untuk meningkatkan perekonomian di Indonesia. Peningkatan perekonomian di Indonesia diselenggarakan berdasarkan demokrasi ekonomi dengan prinsip kebersamaan, efisiensi, berkeadilan, berkelanjutan, berwawasan lingkungan, kemandirian, serta dengan menjaga keseimbangan kemajuan dan kesatuan ekonomi nasional, oleh karena itu perlu didorong dengan adanya kelembagaan perekonomian yang secara langsung akan menciptakan kesejahteraan masyarakat. 
Dalam hal menciptakan kesejahteraan bagi masyarakat dan juga untuk mendukung peningkatan pembangunan perkonomian nasional perlu adanya peraturan yang mengaturnya, demikian pula dengan Perseroan Terbatas. Peraturan yang mengatur tentang Perseroan Terbatas sudah ada di Indonesia pertama kali pada jaman kolonial. Peraturan yang dimaksud adalah yang ada dalam Kitab Undang- Undang Hukum Dagang (Wetboek van Koophandel Staatsblad) Tahun 1847 Nomor

23. Dalam Buku Kesatu Titel Ketiga Bagian Ketiga Pasal 36 sampai dengan Pasal 56, yang perubahannya dilakukan dengan Undang-Undang Nomor 4 Tahun 1971. Kemudian dilahirkanlah Undang-Undang Nomor 1 Tahun 1995. Setelah dirasa peraturan yang berlaku saat itu kurang mendukung perkembangan hukum dan kebutuhan masyarakat karena keadaan ekonomi serta kemajuan ilmu pengetahuan, teknologi, dan informasi sudah berkembang begitu pesat khususnya pada era globalisasi saat ini, maka dilahirkanlah Undang-Undang Nomor 40 Tahun 2007 Tentang Perseroan Terbatas yang menggantikan Undang-Undang Nomor 1 Tahun 1995. Peraturan tersebut dilatarbelakangi oleh peningkatan perekonomian nasional yang membutuhkan peraturan perundang-undangan yang lebih mendukung dunia usaha agar lebih kondusif.

Kehadiran Perseroan Terbatas (PT) sebagai suatu bentuk badan usaha dalam kehidupan sehari-hari tidak lagi dapat diabaikan. Tidak berlebihandikatakan bahwa kehadiran Perseroan Terbatas sebagai salah satu sarana untuk melakukan kegiatan ekonomi sudah menjadi suatu keniscayaan yang tidak dapat ditawar-tawar. Praktik bisnis yang dilakukan oleh para pelaku usaha, baik itu pedagang, industrialis, investor, kontraktor, distributor, banker, perusahaan asuransi, pialang, agen dan lain sebagainya tidak lagi dipisahkan dari kehadiran Perseroan Terbatas. Berbisnis dengan mempergunakan Perseroan Terbatas, baik dalam skala mikro, kecil, menengah maupun berskala besar merupakan model paling banyak dan paling lazim dilakukan. Perseroan Terbatas adalah tungku usaha yang aman dalam dapur bisnis. Dengan sifat liabilitas (liability) risiko yang "terbatas", PT dapat membuat nyenyak tidur pada pendirinya, aman dari kekhawatiran tergerogotinya harta pribadi mereka dalam ihwal bisnis. Karena itu Perseroan Terbatas merupakan bentuk usaha kegiatan ekonomi yang paling disukai saat ini (Binoto Nadapdap, 2018: 1-3).

Limited liability tidak hanya berlaku bagi pemegang saham tetapi juga berlaku bagi organ perseroan yang lainnya yaitu direksi dan komisaris. Direksi dan komisaris harus melakukan semua tugasnya sesuai dengan kewenangan yang diberikan oleh peraturan perundang-undangan dan Anggaran Dasar Rumah Tangga Perseroan Terbatas (ADRT PT). Jadi organ perseroan yang beritikad baik dalam menjalankan tugas dan wewenang tidak dapat dimintai pertanggungjawaban atas kerugian yang diterima perseroan atau pihak ketiga. Tidak selamanya limited liability dapat dilakukan karena adanya suatu sebab. Terbatasnya tanggung jawab perseroan terkoyak dengan prinsip Piercing The Corporate Veil. Organ perseroan akan dimintai pertanggungjawaban jika organ tersebut bertindak melebihi wewenangnya atau telah berbuat lalai atau sengaja sehingga perseroan atau pihak lain mengalami kerugian (Siti Hapsah, 2015: 170).

Doktrin "Piercing the Corporate Veil" tidak hanya terbatas tindakan yang ada pada Undang-Undang Perseroan Terbatas Pasal 3 ayat (2) semata namun mencakup aspek setiap perbuatan hukum yang tidak selaras dengan maksud dan tujuan perseroan yang dapat dilakukan baik oleh Pemegang Saham, Komisaris, dan Direksi perseroan. Piercing the 
corporate veil tidak hanya dapat diterapkan terhadap pemegang saham perseroan, melainkan juga terhadap Dewa Komisaris dan Direksi yang dalam kedudukannya memungkinkan terjadinya penyimpangan atau dilakukannya hal-hal yang dapat mencegah untuk tidak melakukan hal-hal yang sepatutnya dilakukan, yang akan bermuara pada terjadinya kerugian bagi perseroan hingga perseroan tidak sanggup memenuhi seluruh kewajibannya. Ini berarti pengurus perseroan yaitu direksi dan dewan komisaris dapat dimintakan pertanggungjawaban pribadinya, atas kerugian perseroan (Putri Sari, 2015: 46). Oleh sebab itu penulis tertarik untuk mengkaji lebih dalam mengenai Politik Hukum Doktrin Piercing the Corporate Veil dalam Pengelolaan Perseroan Terbatas di Indonesia.

\section{B. Metode Penelitian}

Jenis penelitian hukumyang penulis gunakanadalah penelitian hukum normatif(doctrinal research). Sifat penelitian yang penulis pilih adalah penelitian preskriptif. Pendekatan yang digunakan dalam penelitian ini adalah pendekatan undang-undang (statute approach). Penelitian hukum yang dilakukan oleh penulis bersumber pada bahan hukum primer dan bahan hukum sekunder. Bahan hukum primer terdiri dari Kitab Undang-undang Hukum Perdata dan Undang-Undang Nomor 40 Tahun 2007 tentang Perseroan Terbatas.

\section{Hasil Penelitian dan Pembahasan}

\section{Sejarah Doktrin Piercing the Corporate Veil di Indonesia}

Kitab Undang-undang Hukum Dagang mengatur ketentuan tentang Perseroan Terbatas dalam pasal 36 sampai dengan 55, Buku Kesatu. Bab Ketiga Bagian Ketiga. Seharusnya masih terdapat Pasal 57 dan 58, namun berdasarkan Staatsblad 1939 No. 276, dua pasal tersebut telah dihapus. Hal-hal yang diatur antara lain, syarat pendirian dan tata cara pendirian, permodalan dan saham Perseroan, pengurus Perseroan, tempat kedudukan Perseroan dan jangka waktu berdirinya Perseroan, pembubaran perseroan dan laporan keuangan perseroan (Sulistiowati dan Veri Antoni, 2013: 7). Dilihat dari 19 pasal terkait dengan ketentuan Perseroan Terbatas tersebut, tidak ada satu pasal pun yang menyinggung keberadaan Piercing the Corporate Veil dalam konteks pertanggungjawaban Pemegang Saham, Dewan Komisaris, maupun Direksi. Ketentuan Pasal 40 ayat (2) KUHD menyebutkan: "Para Persero atau Pemegang saham tersebut tidak bertanggungjawab untuk lebih dari pada jumlah penuh andil tersebut".

Pengaturan mengenai doktrin Piercing the Corporate Veil mulai ada pada UndangUndang No. 1 Tahun 1995 tentang Perseroan Terbatas, yaitu adanya pengecualian terhadap prinsip tersebut yang dinyatakan dalam Pasal 3 ayat (2) Undang-Undang No. 1 Tahun 1995, Pasal tersebut membuka ruang pertanggungjawaban pemegang saham melebihi saham yang disetorkan, jika:

a. Persyaratan Perseroan sebagai badan hukum belum atau tidak terpenuhi;

b. Pemegang Saham yang bersangkutan baik langsung maupun tidak langsung dengan itikad buruk memanfaatkan Perseroan semata-mata untuk kepentingan pribadinya;

c. Pemegang Saham yang bersangkutan terlibat dalam perbuatan melawan hukum yang dilakukan oleh Perseroan; atau 
d. Pemegang Saham yang bersangkutan baik langsung maupun tidak langsung secara melawan hukum menggunakan kekayaan Perseroan, yang mengakibatkan kekayaan Perseroan menjadi tidak cukup untuk melunasi hutangnya.

Undang-Undang Perseroan Terbatas Nomor 1 Tahun 1995 juga telah mengatur mengenai pertanggungjawaban Direksi dalam Pasal 85 ayat (2) dan Pasal 90 ayat (2). Pengaturan yang ada dalam Undang-Undang Perseroan Terbatas yang lama belum mengatur lebih luas mengenai Doktrin Piercing the Corporate Veil seperti halnya Undang-Undang Perseroan Terbatas yang baru Nomor 40 Tahun 2007.

Undang-Undang Perseroan Terbatas Nomor 40 Tahun 2007 yang berlaku sampai saat ini mengatur lebih luas tentang doktrin Piercing the Corporate Veil, dengan melimpahkan pertanggungjawaban kepada organ- organ Perseroan Terbatas yakni, Pemegang Saham dalam Pasal 3 ayat (2) dan Pasal 7 ayat (6), Dewan Komisaris dalam Pasal 114 ayat (2) dalam hal tidak melaksanakan fiduciary duty, Pasal 69 ayat (3) dalam hal perhitungan dokumen tahunan tidak benar, dan Pasal 115 ayat (2) dalam hal kepailitan karena kesalahan dan kelalaian Dewan Komisaris. Pengaturan pertanggungjawaban Direksi diatur dalam Pasal 97 ayat (3) dalam hal Direksi tidak melaksanakan fiduciary duty, Pasal 69 ayat (3) dalam hal perhitungan laporan keuangan tidak benar atau menyesatkan, Pasal 95 ayat (4) dalam hal Direksi yang pengangkatannya tidak memenuhi persyaratan dan melakukan perbuatan hukum yang merugikan Perseroan, Pasal 101 ayat (2) dalam hal Direksi tidak melaporkan kepada Perseroan mengenai saham yang dimiliki dan menimbulkan kerugian bagi Perseroan, dan Pasal 104 dalam hal kepailitan terjadi karena kesalahan Direksi.

\section{Politik Hukum Doktrin Piercing the Corporate Veil}

Adanya doktrin Piercing the Corporate Veil dalam hukum positif di Indonesia beralasan sesuai dengan konsideran Undang-Undang Nomor 40 Tahun 2007 yaitu bahwa perekonomian nasional yang diselanggarakan berdasar atas demokrasi ekonomi dengan prinsip kebersamaan, efisiensi berkeadilan, berkelanjutan, berwawasan lingkungan, kemandirian, serta dengan menjaga keseimbangan kemajuan dan kesatuan ekonomi nasional, perlu didukung oleh kelembagaan perekonomian yang kokoh dalam rangka mewujudkan kesejahteraan masyarakat.

Memiliki tujuan untuk melindungi kepentingan stakeholder tersebut. khususnya terkait adanya peluang dari pemegang saham untuk melakukan tindakan hukum antara lain mempengaruhi Perseroan sedemikian rupa sehingga bertentangan dengan asas kepatutan dan keadilan serta untuk memberikan dukungan legalitas terhadap keberadaan Direksi dan Dewan Komisaris Perseroan dalam menjalankan tugasnya masing-masing, maka berkembang doktrin hukum dalam hukum korporasi yang sering disebut Piercing the Corporate Veil. Dilihat dari substansi materi dan idealisme yang terkandung dalam doktrin hukum korporasi ini, sesungguhnya doktrin dimaksud diperlukan sebagai bagian dari pengendalian akhlak para pribadi yang berdiri dibalik organ Perseroan dalam menjalankan usahanya untuk tidak melakukan perbuatan yang tercela yang dapat mencederai rasa keadilan masyarakat. Oleh karena itu, doktrin-doktrin hukum Perseroan tersebut begitu penting (Sandra Dewi, 2018: 384). 
Arti penting pengaturan doktrin Piercing the Corporate Veil dalam hukum positif di Indonesia adalah untuk mewujudkan ketertiban umum dan keadilan. Imlikasi dari tindakan seorang Pemegang Saham yang kontraproduktif terhadap tujuan UndangUndang dapat dijadikan dasar untuk mengabaikan prinsip pemisahan tanggung jawab. Dengan kata lain, apabila perlindungan yang diberikan Undang-Undang kepada investor berupa struktur perusahaan dan pemisahan tanggung jawab menimbulkan kerugian bagi ketertiban umum, maka perlindungan tersebut tidak selayaknya ditegakkan (Sulistiowati dan Veri Antoni, 2013: 27).

Alasan lain dari adanya doktrin-doktrin hukum Perseroan Terbatas dalam hukum positif di Indonesia termasuk doktrin Piercing the Corporate Veil dikarenakan agar terciptanya tata kelola perusahaan yang baik (Good Corporate Governance). Organ Perseroan yang menjalankan Perseroannya dengan prinsip itikad baik sesuai dengan kewenangannya dengan tidak melanggar peraturan perundang-undangan dan juga anggaran dasar Perseroan yang telah ditetapkan, hal tersebut jika dilakukan dengan benar akan menghasilkan perusahaan yang baik dan juga sehat guna meningkatkan keberhasilan usaha dengan baik sesuai dengan prinsip tata kelola perusahaan yang baik (Good Corporate Governance).

Doktin Piercing the Corporate Veil dapat menunjukan fungsi yang bermanfaat. Setelah batas yang tepat dari pertanggungjawaban terbatas dapat dipahami, doktrin Piercing the Corporate Veil dapat memiliki batasannya. Pemahaman tersebut bagaimanapun juga tergantung kepada kebijakan yang ada dalam dasar pertanggungjawaban terbatas. Intinya adalah bahwa Pemegang Saham dapat menikmati pertanggungjawaban terbatas hanya jika mereka telah menjalankan bisnis mereka dengan bertanggung jawab secara finansial. Jika Perseroan tidak mampu membayar utangnya, maka limited liability dapat diterapkan. Pertanggungjawaban terbatas juga dapat berpeluang memfasilitasi perbuatan yang salah oleh Pemegang Saham yang seharusnya tidak diperbolehkan. Kebijakan limited liability seharusnya tidak dapat dikontrol untuk digunakan sebagai alat yang sengaja dibuat untuk mengambil keuntungan dari pihak ketiga tanpa persetujuan mereka dan tanpa kompensasi. Jika Pemegang Saham dapat menggunakan pertanggungjawaban terbatas untuk tujuan tersebut maka pemberian pertanggungjawaban terbatas terkesan sangat murah hati. Maka dari itu Piercing the Corporate Veil memungkinkan pengadilan untuk menyesuaikan pertanggungjawaban terbatas pada kasus- kasus yang benar-benar dijamin (David. K millon, 2007: 1311).

\section{Simpulan}

Politik hukum doktrin Piercing the Corporate Veil merupakan doktrin yang berasal dari sistem hukum common law yang diadaptasi oleh sistem hukum Indonesia. Doktrin Piercing the Corporate Veil sebelumnya tidak diatur dalam Kitan Undang-undang Hukum Dagang sehingga akhirnya munculnya Undang-undang Nomor 1 Tahun 1995 yang mulai mengatur mengenai doktrin Piercing the Corporate Veil. Selanjutnya pengaturan mengenai doktrin ini perluas dalam Undang-Undang Perseroan Terbatas Nomor 40 Tahun 2007 yang mengatur lebih jauh mengenai pertanggungjawaban pribadi organ Perseroan seperti Pemegang Saham dalam Pasal 3 ayat (2), Dewan Komisaris Pasal 114 ayat (3) dan Direksi Pasal 97 ayat (3). Doktrin ini menghilangkan pertanggungjawaban terbatas (limited liability) sesuai dengan 
pasal 3 ayat (1) yang sebelumnya dimiliki oleh Perseroan Terbatas menjadi tidak terbatas. Doktrin Piercing the Corporate Veil ini diterapkan jika Pemegang saham, dewan komisaris, dan Direksi terbukti melakukan perbuatan yang merugikan Perseroan maupun pihak ketiga. Alasan adanya doktrin Piercing the Corporate Veil dalam hukum positif di Indonesia guna menjadi penyeimbang antara hak dan kewajiban organ Perseroan Terbatas sehingga terciptanya tata kelola perusahaan yang baik.

\section{E. Saran}

Kepada pemerintah dan Dewan Perwakilan Rakyat (DPR) dapat memperinci dan memperjelas pengaturan terkait batasan diterapkannya doktrin Piercing the Corporate Veil melalui penambahan Pasal dalam Undang-Undang Perseroan Terbatas khususnya mengenai pertanggungjawaban terbatas organ Perseroan atas tindakan ultra vires yang dianggap melewati kewenangan dan tugasnya sebagai organ Perseroan dalam menjalankan Perseroan dan batasan mengenai kapan organ Perseroan dapat dikatakan telah melanggarfiduciary duty yang telah diberikan oleh Perseroan.

\section{F. Daftar Pustaka}

Binoto Nadapdap. 2018. Hukum Perseroan Terbatas. Jakarta: Jala Permata Aksara.

David K. Millon. 2007. "Piercing the Corporate Veil, Financial Responsibility, and the Limits of Limited Liability”. Emory Law Journal. Volume 56 Nomor 5. Washington: Washington \& Lee University School of Law Scholary..

Putri Sari Harahap. 2015. "Penerapan Asas Piercing the Corporate Veil: Prespektif Tanggung Jawab Direksi Perseroan Terbatas". Nuansa Kenotariatan. Volume 1 Nomor 1. Jakarta: Universitas Jayabaya.

Siti Hapsah Isfardiyana. 2015. "Tanggung Jawab Direksi Perseroan Terbatas dalam Pelanggaran Fiduciary Duty". Padjadjaran Jurnal Ilmu Hukum. Volume 2 Nomor 1. Bandung: Universitas Padjadjaran.

Sulistiowati dan Veri Antoni. 2013. "Konsistensi Penerapan Doktrin Piercing the Corporate Veil pada Perseroan Terbatas di Indonesia". Yustisia. Volume 2 Nomor 3. Yogyakarta: Universitas Gajah Mada.

Sandra Dewi. 2018. "Mengenal doktrin dan prinsip Piercing the Corporate Veil dalam hukum perusahaan". Soematra Law Review. Volume 1 Nomor 2. Riau: Universitas Lancang Kuning. 